\title{
Mathematical Reasoning in Complex Function Textbook Exercises
}

\author{
Senja Putri Merona \\ Mathematics Education Departement \\ Muhammadiyah University of Ponorogo \\ Ponorogo, Indonesia \\ senjaputrimerona@gmail.com
}

\author{
Erika Eka Santi \\ Mathematics Education Departement \\ Muhammadiyah University of Ponorogo \\ Ponorogo, Indonesia \\ senjaputrimerona@gmail.com
}

\begin{abstract}
The aim of this paper is to study some strategies that are possible to use in solving the exercises in undergraduate complex function textbooks. Furthermore, it will be studied the indicators of mathematical reasoning ability that appear in the exercises. The results of this study indicate the type of exercises that can be used to develop certain indicators of mathematical reasoning abilities. The results show that most of the exercises require only procedural capability, while concept-based exercises require reasoning skills ranging from simple to complex.
\end{abstract}

Keywords-mathematical reasoning; exercises; textbook

\section{INTRODUCTION}

The estuary from the purpose of high education according to Law Constitution Number 12 Year 2012 is the exposing of high education alumnae to the public in devotion and research that reasoning basis in order to increasing the prosperity and educate nation's life. Reasoning as the basis of research activity and meaningful devotion that all of activity in purpose to increasing the prosperity and educate the nation must based on logical thinking. Reasoning in this case is the foundation of thought and decision making related with problem, needs, solution and advantages that is gotten.

In Permenristekdikti Number 44 Year 2015 are stated three aspects in High education Graduates Competence Standard. One of three aspects is knowledge aspect. This aspect includes concept comprehension, theory, method, and/or philosophy in certain knowledge systematically that is gained from reasoning and learning process. The thing that needs to be underlined is learning process for comprehending certain knowledge involves the reasoning process inside. Specifically, at Program Study of Mathematic Education, the increasing of mathematic reasoning ability should be integrated in every subject.

The process of solving problem is hoped not only stop until get the final score. University student is also hoped can understand the rationalization in solution that is gotten. Therefore, build argument and defend argument is very important ability for university student. With this ability, university student can mean every procedure that is done in getting settlement.

Mathematics reasoning is activity to connect new knowledge with the knowledge that have already possessed. Furthermore, The real reasoning is reset the knowledge that have already gotten. Mathematics reasoning includes the ability to find conjecture, analysis, evaluation, generalization, connection, synthetic, unroutine resolving problem and justification or proofing. From the opinion above, it can be concluded that reasoning can be meaned as activity and ability. In activity context, reasoning has a strong relationship with thinking activity. Meanwhile, in ability context, commonly someone who reasoning is able to analyses and make conclusion related with problem based on data, fact, and symptom.

There are some things that can support the development of university student's reasoning. One of them is with doing reasoning tasks. Task in this case such as exercise, has important role to push the development of understanding and reasoning for university student. [6] states that "new task" where the resolving procedure indirectly available or ready to used will push the university student for optimizing mathemic knowledges that already had before. The result of the research by [3] states that mathematic component in mathematic reasoning task can support mathematical reasoning. Reasoning is used in solving problem (Mathematic task) and also for deciding is the solution from the problem is right. The university student will involve into mathematical reasoning when is asked to conclude logically, recognize kind and justification level, and uses mathematic language for making explanation

Mathematics' task is always existing in every text book that is used in college. Text book has important role in colleague process. This thing is the same as [2] states that text book is the most important artifact in mathematics education. [1] states that text book is main source for implementing the lecture and exercise for university student. The text book that facilitate university student with reasoning task will push the university student for developing the ability of reasoning.

[1] stated that most of students' activities in the class is finishing the task in the text book. However, [5] states that most of university student do not have time for finishing all recommended task in text book. Therefore, the role of lecture in choosing and filtering the task from the text book that is used much needed in learning process. By finishing the appropriate task, the ability of university student will develop based on the arranged 'purposes. 


\section{RESULTS AND DISCUSSION}

Based on the description above, it is necessary to analyze the indicator of mathematical reasoning in text book that is used at complex function courses in college. By knowing the mathematical reasoning indicator in the exercises of Complex Faction text book, lecturer can choose the right task for developing the certain ability. The right task is hoped can support the achievement of learning purposes that have already designed.

\section{Methodology}

The methodology that is used in this research is analytic descriptive method. Descriptive method is used to identify and explain the element that is glazed in this research. Analytic method is used to describe and review the exercise's characteristic in complex function text book based on the indicator of mathematical reasoning ability.

The subject of this research is exercises related with analytic functions topic and elementary functions. The source of the data in this research is complex function text book entitled "A First Course in Complex Analysis with Application" by Dennis G zill and Patrick D. Shahanan that is published by Jones and Bartlett Publisher in 2003. Data is collected by documentation technique.

The research data analysis is done through four steps. First step, describing the indicator of reasoning ability that will be used as reference in data analysis. Second step, the research data in exercises are described based on its characteristic. Third step, analysis is done through exercises that have been described based on indicator of reasoning ability. Fourth step is interpreting the analysis result and serve it into diagram. The composition of mathematical reasoning ability spreading in this research is processed with the formula (1) as follows.

$$
P i j=\frac{\sum X i}{\sum Y j}
$$

where

$P i j \quad$ : the percentage of question with reasoning indicator to$i$

$\sum X i$ : the amount of question with indicator to- $i$

$\sum Y j:$ the total of question in sub chapter to- $j$

\section{A. Results}

Exercises on each sub chapter of the book that is analyzed divides into two parts. The first part is Exercises and the second is Focus on Concepts. In Chapter 3, about Analytic Functions, there are three sub-chapter that are analyzed. Sub-chapter 3.1 about "Differentiability and Analyticity" consist of 30 questions in Exercises and 5 questions Focus on Concepts. Sub-chapter 3.2 is about "Cauchy-Riemann Equations" consist of 26 questions in Exercises and 9 questions Focus on Concept. Sub-chapter 3.3 is about "Harmonic Functions" consist of 16 questions in Exercises and 6 questions Focus on Concepts. Meanwhile, in chapter 4 is about Elementary Functions, there are 4 sub-chapter that are analyzed, they are sub-chapter 4.1 about Exponential and Logarithmic Functions, sub-chapter 4.2 is about Complex Powers, sub-chapter 4.3 about Trigonometric and Hyperbolic Functions, and sub-chapter 4.4 about Invers Trigonometric and Hyperbolic Functions. Sub-chapter 4.1 consists of 46 questions in Exercises and 10 questions in Focus on Concepts, sub-chapter 4.2 consist of 18 questions in Exercises and 6 questions in Focus on Concepts, sub-chapter 4.3 consists of 36 questions in Exercises and 16 questions in Focus on Concepts, sub- chapter 4.4 consist of 16 questions in Exercises and 6 questions in Focus on Concepts.

Before analyzing the exercises in text book, first decide the indicator of mathematical reasoning ability that will be the basic of analysis. Based on the literature study and conformity with the material, are gained 7 indicators. They are (1) giving examples and non-examples, (2) arranging the proof based on applicable characteristic, (3) making a conjecture, (4) verifying the conjecture, (5) identifying the necessary and sufficient condition of a statement, (6) generalizing a statement using known characteristics, and (7) using analogy and informal explanation about the reason of the conjectures.

The result of analysis through some question in Complex Function text book is stated by Table 1.

Based on the analysis result through questions in complex function text book, can be distributed mathematical reasoning indicator in each sub chapter that is stated at Table 2 . From this analysis result then count the percentage of question's number with reasoning indicator. The results are shown at Table 3.

TABLE $1 \quad$ EXAMPLE OF RESUlT'S ANALYSIS EXERCISE IN FUNCTION COMPLEX TEXT BOOK

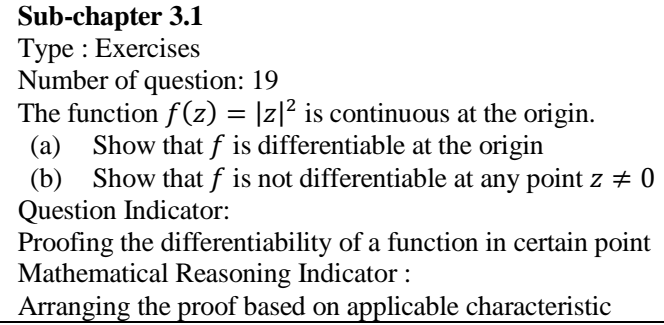


TABLE 1 EXAMPLE OF RESULT'S ANALYSIS EXERCISE IN FUNCTION COMPLEX TEXT BOOK

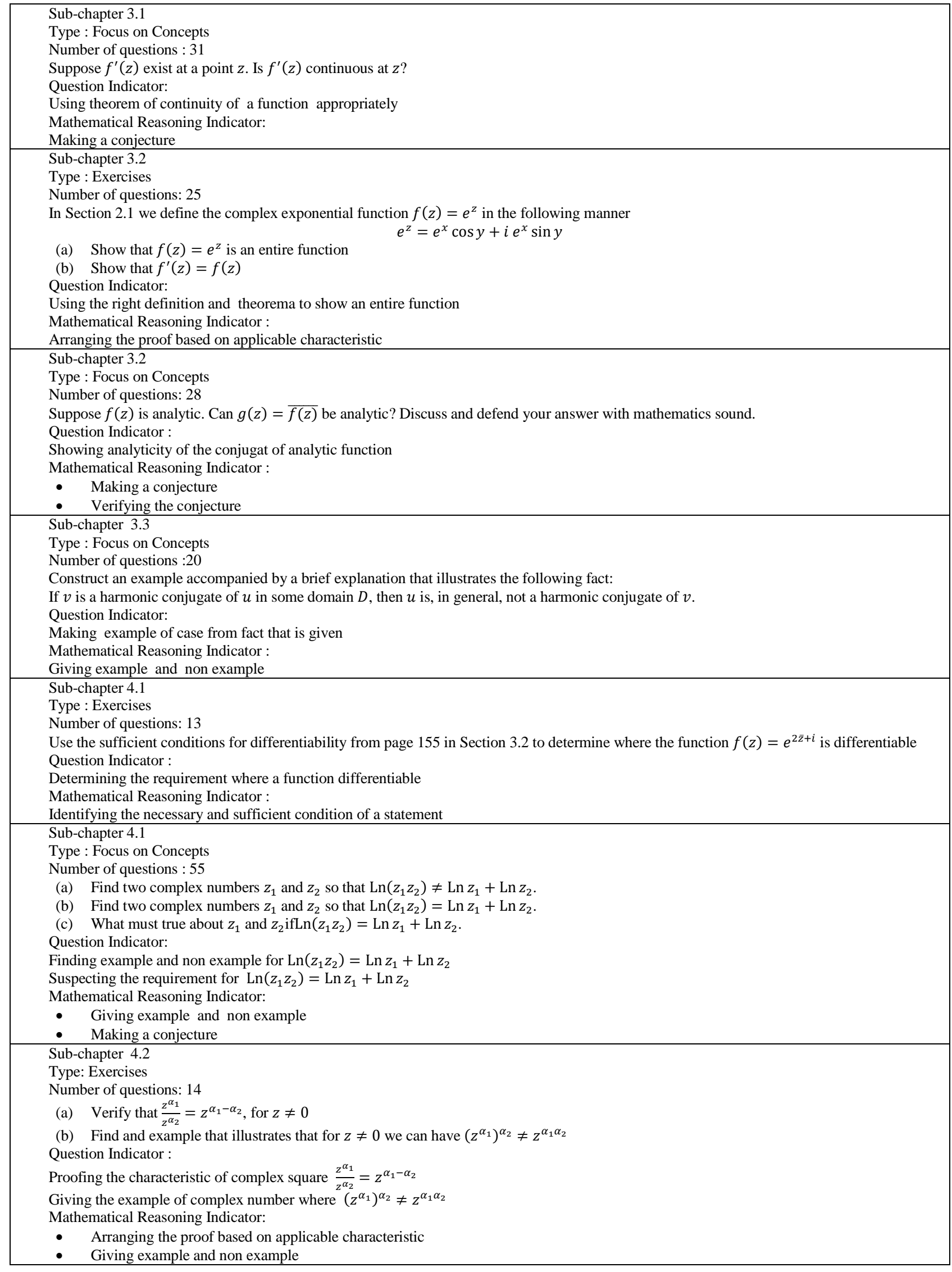


TABLE 1 EXAMPLE OF RESULT's ANALYSIS EXERCISE IN FUNCTION COMPLEX TEXT BOOK

Sub-chapter 4.2

Type : Focus on Concepts

Number of questions : 20

If $\alpha=x+i y$ where $x=0, \pm 1, \pm 2, \ldots$, then what can you say about $1^{\alpha}$ ?

Question Indicator :

Making a conjecture about $1^{\alpha}$ if it is given $\alpha=x+i y$ where $x=0, \pm 1, \pm 2, \ldots$,

Mathematical Reasoning Indicator :

Making a conjecture

Sub-chapter 4.3

Type : Exercises

Number of questions : 29-32

In Problem 29-32, verify the given hyperbolic identity.

29. $\cosh ^{2} z-\sinh ^{2} z=1$

30. $\sinh \left(z_{1}+z_{2}\right)=\sinh z_{1} \cosh z_{2}+\cosh z_{1} \sinh z_{2}$

31. $|\sinh z|^{2}=\sinh ^{2} x+\sinh ^{2} y$

32. $\operatorname{Im}(\cosh z)=\sinh x \sinh y$

Question Indicator :

Proofing the identity of hyperbolic function

Mathematical Reasoning Indicator :

Arranging the proof based on applicable characteristic

Sub-chapter 4.3

Type : Focus on Concepts

Number oq questions: 44

Without calculating the partial derivatives, explain why $\sin x \cosh y$ and $\cos x \sinh y$ are harmonic functions in $C$

Question Indicator:

Giving explanation with simple reason related to harmonic function

Mathematical Reasoning Indicator:

Using analogy and informal explanation about the reason of the conjectures

Sub-chapter 4.4

Type : Focus on Concepts

Number of questions : 17

Derive formula (4) for $\cos ^{-1} z$ by modifying the procedure used to derive the formula for arcsine on page 215 .

Question Indicator:

Derive the pattern function from pattern and procedure that had been gotten before

Mathematical Reasoning Indicator:

Generalizing a statement using known characteristics

TABLE 2 THE DISTRIBUTION OF REASONING INDICATOR IN EXERCISE

\begin{tabular}{|c|c|c|c|c|c|c|}
\hline \multirow{2}{*}{ Chapter } & \multirow{2}{*}{$\begin{array}{c}\text { Sub } \\
\text { Chapter }\end{array}$} & \multirow{2}{*}{$\begin{array}{l}\text { Group of } \\
\text { Exercise }\end{array}$} & \multicolumn{2}{|c|}{ The total of question } & \multirow{2}{*}{$\begin{array}{c}\text { Number } \\
\text { of } \\
\text { question }\end{array}$} & \multirow{2}{*}{ Indicator } \\
\hline & & & Total & Reasoning & & \\
\hline \multirow{12}{*}{3} & \multirow{5}{*}{3.1} & Exercises & 30 & 4 & $19-22$ & Arranging the proof based on applicable characteristic \\
\hline & & \multirow{4}{*}{$\begin{array}{c}\text { Focus on } \\
\text { Concept }\end{array}$} & \multirow{4}{*}{5} & \multirow{4}{*}{5} & $31-32$ & Making a conjecture \\
\hline & & & & & 33 & Arranging the proof based on applicable characteristic \\
\hline & & & & & 34 & Verifying the conjecture \\
\hline & & & & & 35 & Arranging the proof based on applicable characteristic \\
\hline & \multirow{7}{*}{3.2} & Exercises & 26 & 2 & $25-26$ & Arranging the proof based on applicable characteristic \\
\hline & & \multirow{6}{*}{$\begin{array}{l}\text { Focus on } \\
\text { Concept }\end{array}$} & \multirow{6}{*}{9} & & \multirow{2}{*}{$27-28$} & Making a conjecture \\
\hline & & & & 9 & & Examine the truth of alligance \\
\hline & & & & & 29-31 & Arranging the proof based on applicable characteristic \\
\hline & & & & & 32 & Making a conjecture \\
\hline & & & & & 33 & Arranging the proof based on applicable characteristic \\
\hline & & & & & $34-35$ & Arranging the proof based on applicable characteristic \\
\hline
\end{tabular}


TABLE 2 The distribution of Reasoning Indicator in Exercise

\begin{tabular}{|c|c|c|c|c|c|c|}
\hline \multirow{2}{*}{ Chapter } & \multirow{2}{*}{$\begin{array}{c}\text { Sub } \\
\text { Chapter }\end{array}$} & \multirow{2}{*}{$\begin{array}{l}\text { Group of } \\
\text { Exercise }\end{array}$} & \multicolumn{2}{|c|}{ The total of question } & \multirow{2}{*}{$\begin{array}{c}\text { Number } \\
\text { of } \\
\text { question }\end{array}$} & \multirow{2}{*}{ Indicator } \\
\hline & & & Total & Reasoning & & \\
\hline \multirow{4}{*}{3} & \multirow{4}{*}{3.3} & Exercises & 16 & 4 & $13-16$ & Arranging the proof based on applicable characteristic \\
\hline & & \multirow{3}{*}{$\begin{array}{l}\text { Focus on } \\
\text { Concept }\end{array}$} & \multirow{3}{*}{6} & \multirow{3}{*}{4} & 19 & Making a conjecture \\
\hline & & & & & 20 & Giving example and non example \\
\hline & & & & & $21-22$ & Arranging the proof based on applicable characteristic \\
\hline \multirow{13}{*}{\multicolumn{2}{|c|}{4.1}} & \multirow{2}{*}{ Exercises } & \multirow{2}{*}{46} & \multirow{2}{*}{6} & $13-14$ & $\begin{array}{l}\text { Identifying the necessary and sufficient condition of a } \\
\text { statement }\end{array}$ \\
\hline & & & & & $37-40$ & $\begin{array}{l}\text { Identifying the necessary and sufficient condition of a } \\
\text { statement }\end{array}$ \\
\hline & & \multirow{11}{*}{$\begin{array}{l}\text { Focus on } \\
\text { Concept }\end{array}$} & \multirow{11}{*}{10} & \multirow{11}{*}{9} & 47 & Arranging the proof based on applicable characteristic \\
\hline & & & & & 48 & Arranging the proof based on applicable characteristic \\
\hline & & & & & 49 & $\begin{array}{l}\text { Identifying the necessary and sufficient condition of a } \\
\text { statement }\end{array}$ \\
\hline & & & & & 50 & Arranging the proof based on applicable characteristic \\
\hline & & & & & & Arranging the proof based on applicable characteristic \\
\hline & & & & & 52 & $\begin{array}{l}\text { Identifying the necessary and sufficient condition of a } \\
\text { statement }\end{array}$ \\
\hline & & & & & $53-54$ & Arranging the proof based on applicable characteristic \\
\hline & & & & & 55 & Making a conjecture \\
\hline & & & & & (נ) & Giving example and non-example \\
\hline & & & & & 5 & Making a conjecture \\
\hline & & & & & o & Examining the truth of alligance \\
\hline & \multirow{6}{*}{4.2} & \multirow{3}{*}{ Exercises } & \multirow{3}{*}{18} & \multirow{3}{*}{2} & 13 & Arranging the proof based on applicable characteristic \\
\hline & & & & & & Arranging the proof based on applicable characteristic \\
\hline & & & & & 14 & Giving example and non-example \\
\hline & & \multirow{3}{*}{$\begin{array}{l}\text { Focus on } \\
\text { Concept }\end{array}$} & \multirow{3}{*}{6} & \multirow{3}{*}{5} & 20 & Making a conjecture \\
\hline & & & & & $21-22$ & Arranging the proof based on applicable characteristic \\
\hline & & & & & $23-24$ & Making a conjecture \\
\hline & \multirow{8}{*}{4.3} & \multirow[t]{2}{*}{ Exercises } & \multirow{2}{*}{36} & \multirow{2}{*}{8} & $13-16$ & Arranging the proof based on applicable characteristic \\
\hline & & & & & $29-32$ & Arranging the proof based on applicable characteristic \\
\hline & & & & & 37 & Arranging the proof based on applicable characteristic \\
\hline & & & & & & Making a conjecture \\
\hline & & Concept & & & $39-40$ & Verifying the conjecture \\
\hline & & & 16 & 8 & 43 & Arranging the proof based on applicable characteristic \\
\hline & & & & & 44 & $\begin{array}{l}\text { Using analogy and informal explanation about the } \\
\text { reason of the conjectures }\end{array}$ \\
\hline & & & & & 45 & Arranging the proof based on applicable characteristic \\
\hline
\end{tabular}


TABLE 2 The distribution of Reasoning Indicator in Exercise

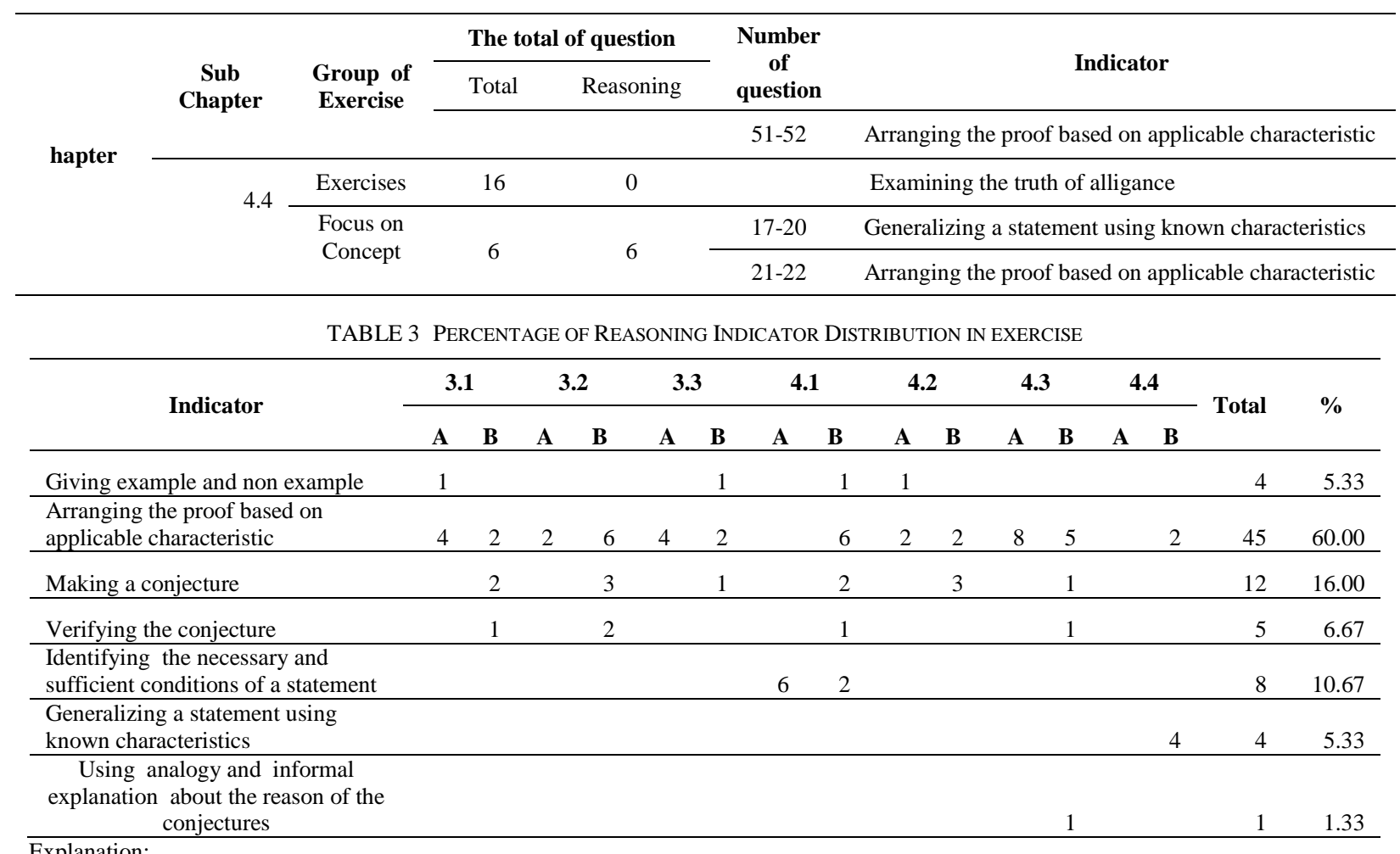

A: Questions of Exercises group

B: Question of Focus on Concepts group

The total of question that are analyzed in this research is 246 Exercise type and 68 Focus on Concepts type. The questions spread into $7 \mathrm{sub}$ chapter. The total of question for each subchapter 3.1 and sub-chapter 3.2 is 35 questions. Sub-chapter 3.3 consist of 22 questions, Sub-chapter 4.1 consist of 56 questions.
Sub-chapter 4.2 consist of 24 questions. Sub-chapter 4.3 consist of 52 questions. Sub-chapter 4.4. consist of 22 questions. From the total of these questions, counted the percentage of reasoning questions in each chapter. The result is stated in Table 4.

TABLE 4 THE PERCENTAGE OF REASONING QUESTION FOR EACH CHAPTER

\begin{tabular}{|c|c|c|c|c|c|c|c|c|c|c|}
\hline \multirow{2}{*}{$\begin{array}{l}\text { Group of } \\
\text { Question }\end{array}$} & \multicolumn{7}{|c|}{ The reasoning question } & \multirow{2}{*}{$\begin{array}{c}\text { Total of Reasoning } \\
\text { question }\end{array}$} & \multirow{2}{*}{$\begin{array}{l}\text { The amount of } \\
\text { question total }\end{array}$} & \multirow[b]{2}{*}{$\%$} \\
\hline & 3.1 & 3.2 & 3.3 & 4.1 & 4.2 & 4.3 & 4.4 & & & \\
\hline Exercises & 5 & 2 & 4 & 6 & 3 & 8 & 0 & 24 & 188 & 13 \\
\hline $\begin{array}{l}\text { Focus on } \\
\text { Concepts }\end{array}$ & 5 & 11 & 4 & 12 & 5 & 8 & 6 & 50 & 58 & 86 \\
\hline Total & 10 & 13 & 8 & 18 & 8 & 16 & 6 & & & \\
\hline Percentage & 28.57 & 37.14 & 36.36 & 32.14 & 33.33 & 30.77 & 27.27 & & & \\
\hline
\end{tabular}

Besides the reasoning question, Complex Function Text Book also consists of routine exercise question. From 246 question that are analyzed, 174 questions are non-reasoning question. Table 5 gives the example of non-reasoning question.
TABLE 5 EXAMPLE OF NON-REASONING QUESTIONS

\begin{tabular}{|c|}
\hline $\begin{array}{l}\text { Exercises } 3.1 \text { Number } 1-6 \\
\text { In problems 1-6, use (1) of Definition } 3.1 \text { to find } f^{\prime}(z) \text { for the given function. } \\
\begin{aligned} \text { 1. } & f(z)=9 i z+2-3 i \\
\text { 2. } & f(z)=15 z^{2}-4 z+1-3 i \\
\text { 3. } & f(z)=i z^{3}-7 z^{2} \\
\text { 4. } & f(z)=\frac{1}{z} \\
\text { 5. } & f(z)=z-\frac{1}{z} \\
\text { 6. } & f(z)=-z^{-2}\end{aligned}\end{array}$ \\
\hline
\end{tabular}


TABLE 5 Example of non-reasoning questions

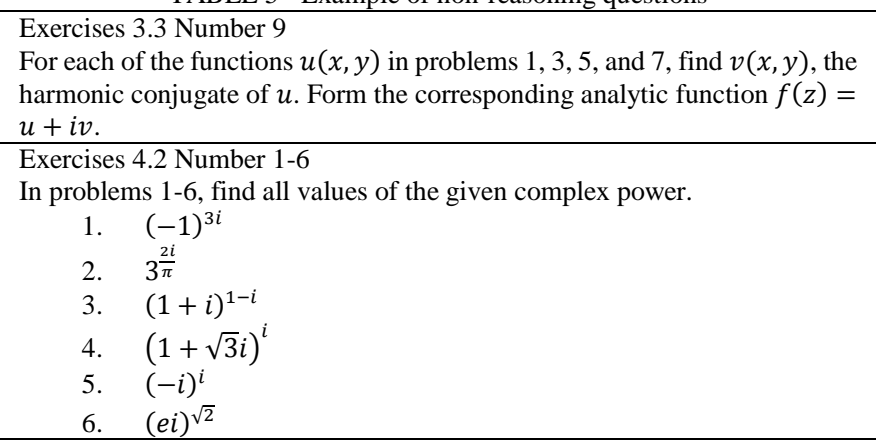

\section{B. Discussion}

From the analysis is gained that in two chapters that are analyzed, contains reasoning and non-reasoning type of question. The non-reasoning type is more dominate than reasoning question. From the total of 246 question that are analyzed, only $29.27 \%$ question are reasoning question, meanwhile the remaining are non-reasoning question. This mark is still little because not reach a half from all the questions. If reviewed from the group of question, question from Focus on Concept group contains much reasoning question than Exercises group. From 58 questions in Focus on Concepts groups, $86 \%$ are reasoning type question. Meanwhile, in Exercises group, only 24 from 188 questions are about reasoning question.

Reviewing from the distribution of reasoning question in each sub chapter, no sub chapter that have percentage more than $50 \%$. In Chapter 3 about Analytic functions, sub-chapter 3.1 contains of reasoning question is about $28.57 \%$, sub-chapter 3.2 is about $7.14 \%$ reasoning question, and sub-chapter 3.3 consist of $36.36 \%$ reasoning question. In chapter 4 about Elementary functions, sub-chapter 4.1 contains of $32.14 \%$ reasoning question, sub-chapter 4.2 consist of $33.33 \%$ reasoning question, sub chapter 4.3 consist of $30.77 \%$ reasoning question, and sub-chapter 4.4 consist of $27.27 \%$ reasoning question.

The seventh of mathematical reasoning indicator that have already reviewed before just appeared in reasoning type of exercises. Each indicator appears with different frequentation. Look From the percentage, question with indicator using the analogy and informal explanation about the reason of making conjecture has the least percentage, 1, $33 \%$. Question with indicator doing generalization by known characteristic and give the example and non example appear with the same percentage, $5.33 \%$. Next, the question with indicator verifying the conjecture has the percentage of appearance $6.67 \%$. Indicator identifying the necessary and sufficient conditions of a statement gets $10.67 \%$. The question by indicator making a conjecture has a percentage of $16 \%$. Question with indicator arranging proof based on the applicable characteristic is the much dominated all the questions, which is $60 \%$ of appearance.

Commonly, Complex Function subject is a study that involves the properties and characteristics in the set of complex number. In this research, the material of complex function that is reviewed is related with analytic functions and elementary functions. The material of analytic function consist of sub chapter about differentiability, analyticity, Cauchy-Riemann equation, and harmonic function, meanwhile the material of elementary functions contain of exponential and logarithmic function, complex powers, trigonometric and hyperbolic functions, and invers trigonometric and hyperbolic function. If it saw from its characteristic, most of the materials discuss about criteria and characteristics. For example, in differentiability material, it is discussed about differentiability criteria of a function. In material of exponential and logarithmic functions, it is discussed about the characteristic of a mapping by exponential and logarithmic function. From here, it can be understood that the much reasoning indicator is arrange proof based on applicable properties.

Sometimes, material with this characteristic traps with procedural question that related with finding the solving problem using behavior and characteristic that have been given. Therefore, most of question in this material is non reasoning question. The question of non-reasoning that appear more focus on university students' understanding in using definition, theorem, or the characteristics that are given in solving problem. However, mathematical reasoning still strives for being developed integrate in every subject at Program study of Mathematic education. This thing is the same as [7] that is the development of cognitive level instrument go through reasoning level and not only knowledge and application are needed to be done. Once in the strategy choice resolving problem is still related with reasoning process, however this thing can be finished by the superficial of mathematic ability.

\section{CONCLUSIONS}

On the effort of developing mathematical reasoning ability of university student, every subject is hoped can integrate the reasoning into the colleague in the class. Text book as one of supporter at learning process consist of task component like exercise. This exercise should be chosen appropriately for supporting the purpose of learning as wish.

From the result of discussion is gained that most of the task in two chapters of text book that is examined, most of them contain of non-reasoning exercises. On Exercises group, $13 \%$ of exercises contains of question with reasoning type. From Focus on Concepts group, $86 \%$ questions are reasoning question. The most appear indicator is arranging the proof based on applicable properties. The least is indicator using analogy and informal explanation about the reason of making conjecture in this text book.

Non reasoning question that are found in this text book can give advantage for practicing the skill of counting and student's algebra manipulation. However, lecture need to reexamine what ability that wants to be developed for university student and then choose the appropriate task based on the indicator that is determined. For fulfilling the understanding needs related with definition, theorem, and applicable character can be given exercise to Exercises group. Question from this group can be given after the lecture explains definition or 
theorem in certain topic. Thus, the university student can more understandable in the using. For supporting the development of university student's reasoning ability, the task is better to be given by using this book, about questions in Focus on Concepts group.

\section{REFERENCES}

[1] Boesen, J., Helenius, O., Bergqvist, E., Bergqvist, T., Lithner, J., Palm, T., \&Palmberg, B. Developing mathematical competence: From the intendedto the enacted curriculum. The Journal of Mathematical Behavior, 33, pp. 72-87, 2014.

[2] Fan, L., Zhu, Y., \& Miao, Z. Textbook research in mathematics education: development status and directions. ZDM, 2013, pp. 1-14.
[3] Frosch, Caren and Simms, Victoria. Understanding the role of reasoning ability in mathematical achievement. In: EuroAsianPacific Joint Conference on Cognitive Science. EuroAsianPacific Joint Conference on Cognitive Science. 2015, 6 pp. [Conference contribution]

[4] Kemendiknas. Undang-Undang Nomor 12 Tahun 2012 tentang Pendidikan Tinggi. 2012

[5] Lithner, J. Mathematical reasoning in calculus textbook exercises. The Journal of Mathematical Behavior, 23(4), pp. 405-427 2004.

[6] Mueller, Yankelewitz, and Maher. Teachers Promoting Student Mathematical Reasoning. Investigations in Mathematics Learning, The Research Council on Mathematics Learning, 7(2), 2014, pp. 1-20

[7] Rosnawati, R. Kemampuan Penalaran Matematika Siswa SMP Indonesia pada TIMSS 2011. In Prosiding Seminar Nasional Penelitian, Pendidikan danPenerapan MIPA, Fakultas MIPA, Universitas Negeri Yogyakarta (Vol. 18). 2013 